\title{
The experimental combination of rTMS and fMRI reveals the functional relevance of parietal cortex for visuospatial functions.
}

Citation for published version (APA):

Sack, A. T., Hubl, D., Prvulovic, D., Formisano, E., Jandl, M., Zanella, F. E., Maurer, K., Goebel, R. W., Dierks, T., \& Linden, D. E. (2002). The experimental combination of rTMS and fMRI reveals the functional relevance of parietal cortex for visuospatial functions. Cognitive Brain Research, 13, 85-93. https://doi.org/10.1016/S0926-6410(01)00087-8

Document status and date:

Published: 01/01/2002

DOI:

10.1016/S0926-6410(01)00087-8

Document Version:

Publisher's PDF, also known as Version of record

Document license:

Taverne

Please check the document version of this publication:

- A submitted manuscript is the version of the article upon submission and before peer-review. There can be important differences between the submitted version and the official published version of record.

People interested in the research are advised to contact the author for the final version of the publication, or visit the DOI to the publisher's website.

- The final author version and the galley proof are versions of the publication after peer review.

- The final published version features the final layout of the paper including the volume, issue and page numbers.

Link to publication

\footnotetext{
General rights rights.

- You may freely distribute the URL identifying the publication in the public portal. please follow below link for the End User Agreement:

www.umlib.nl/taverne-license

Take down policy

If you believe that this document breaches copyright please contact us at:

repository@maastrichtuniversity.nl

providing details and we will investigate your claim.
}

Copyright and moral rights for the publications made accessible in the public portal are retained by the authors and/or other copyright owners and it is a condition of accessing publications that users recognise and abide by the legal requirements associated with these

- Users may download and print one copy of any publication from the public portal for the purpose of private study or research.

- You may not further distribute the material or use it for any profit-making activity or commercial gain

If the publication is distributed under the terms of Article 25fa of the Dutch Copyright Act, indicated by the "Taverne" license above, 


\title{
The experimental combination of rTMS and fMRI reveals the functional relevance of parietal cortex for visuospatial functions
}

\author{
A.T. Sack ${ }^{\mathrm{a}, 1}$, D. Hubl ${ }^{\mathrm{a}, \mathrm{e}, 1}, *$, D. Prvulovic ${ }^{\mathrm{a}}$, E. Formisano ${ }^{\mathrm{d}}$, M. Jandl ${ }^{\mathrm{a}}$, F.E. Zanella ${ }^{\mathrm{b}}$, \\ K. Maurer ${ }^{\mathrm{a}}$, R. Goebel ${ }^{\mathrm{d}}$, T. Dierks ${ }^{\mathrm{e}}$, D.E.J. Linden ${ }^{\mathrm{a}, \mathrm{c}}$ \\ ${ }^{a}$ Department of Psychiatry, Division of Neurophysiology and Neuroimaging, Johann Wolfgang Goethe-Universität, Theodor-Stern-Kai 7, \\ DE-60590 Frankfurt, Germany \\ ${ }^{\mathrm{b}}$ Department of Neuroradiology, Johann Wolfgang Goethe-Universität, Theodor-Stern-Kai 7, DE-60590 Frankfurt, Germany \\ ${ }^{\mathrm{c}}$ Max-Planck-Institut für Hirnforschung, Deutschordenstrasse 46, DE-60528 Frankfurt, Germany \\ ${ }^{\mathrm{d}}$ Department of Psychology, University of Maastricht, P.O. Box 616, 6200 MD Maastricht, The Netherlands \\ ${ }^{\mathrm{e}}$ Department of Psychiatry, University of Bern, Bolligenstrasse 111, CH-3000 Berne 60, Switzerland
}

Accepted 7 August 2001

\begin{abstract}
We combined repetitive transcranial magnetic stimulation (rTMS) and functional magnetic resonance imaging (fMRI) to investigate the functional relevance of parietal cortex activation during the performance of visuospatial tasks. fMRI provides information about local transient changes in neuronal activation during behavioural or cognitive tasks. Information on the functional relevance of this activation was obtained by using rTMS to induce temporary regional deactivations. We thereby turned the physiological parameter of brain activity into an independent variable controlled and manipulated by the experimenter and investigated its effect on the performance of the cognitive tasks within a controlled experimental design. We investigated cognitive tasks that were performed on the same visual material but differed in the demand on visuospatial functions. For the visuospatial tasks we found a selective enhancement of fMRI signal in the superior parietal lobule (SPL) and a selective impairment of performance after rTMS to this region in comparison to a control group. We could thus show that the parietal cortex is functionally important for the execution of spatial judgements on visually presented material and that TMS as an experimental tool has the potential to interfere with higher cognitive functions such as visuospatial information processing. (c) 2002 Elsevier Science B.V. All rights reserved.
\end{abstract}

Theme: Neural basis of behavior

Topic: Cognition

Keywords: Parietal cortex; Functional lesion; Visuospatial function; rTMS; fMRI

\section{Introduction}

Activation of parietal cortex during the execution of visuospatial tasks has been found in a number of recent functional neuroimaging studies in humans. An increase in the blood oxygen level-dependent (BOLD) signal, mea-

\footnotetext{
*Corresponding author. University Hospital of Clinical Psychiatry Bern, Department of Psychiatric Neurophysiology, Bolligenstrasse 10, CH-3000 Berne 60, Switzerland. Tel.: +41-31-930-9752; fax: +41-31930-9961.

E-mail address: hubl@puk.unibe.ch (D. Hubl).

${ }^{1}$ These authors contributed equally to the work.
}

sured with functional magnetic resonance imaging (fMRI), or in regional cerebral blood flow (rCBF), measured by positron emission tomography (PET), was observed in the superior parietal lobule (SPL) during the performance of tasks dependent on location matching [19], mental rotation of two- [2] and three-dimensional (3D) [11] objects, mirror reading $[17,28]$, surface orientation [34], and the discrimination of angle differences of visually presented [13] and mentally imagined [35] analogue clocks.

Although the methods of functional neuroimaging provide evidence for transient local increases in neuronal activity, they reveal little about the nature of this activity, e.g., whether it is inhibitory or excitatory [31] or whether 
the task-correlated activation in one brain area might be a non-functional by-product of activation in other areas. This methodological limitation of causal interpretations is due to the experimental designs used in neuroimaging studies. In these studies brain activity is measured while subjects execute different cognitive tasks. The different operationalizations of neuronal activity are the dependent variables whose variance is analyzed with regard to the chosen stimulation protocol (the cognitive task). The influence of the execution of the different tasks on brain activity can then be analyzed. Functional neuroimaging can thus establish associations but not causal relationships between task performance and patterns of cortical activation. The technique of transcranial magnetic stimulation (TMS) provides a possibility to manipulate brain activity as an independent variable and to investigate its influence on the performance of different cognitive tasks. TMS thus can be regarded as a tool for the investigation of causal relationships between the physiological parameters measured as operationalizations of brain activity and the behavioural data of task performances.

Repetitive TMS (rTMS) uses trains of repetitive magnetic pulses to induce an electrical field in the neural tissue below the coil $[18,38]$. The nature of this effect, inhibitory or excitatory, has been found to be dependent on the frequency used in rTMS $[18,25]$. Several studies report an inhibitory effect of low-frequency ( $1 \mathrm{~Hz}$ or less) rTMS $[10,23]$ while high-frequency (5 Hz and more) rTMS has been shown to lead to an increase of cortical excitability [27]. This frequency dependent rTMS effect has been demonstrated during [22,26], as well as for minutes following the TMS stimulation [10,23,26,27]. Repetitive TMS thus leads to a transient, partial 'functional lesion' of a specific cortical region [23,38]. Single-pulse TMS has been used to study the temporal aspects of different functions by disrupting information processing with triggered TMS pulses [1,16,36].

Several studies used rTMS or single-pulse TMS to influence neuronal activation and to investigate the functional relevance of brain activation for different behavioural or cognitive functions such as visual imagery [23], visual shape-processing [4] and hemispheric asymmetry in visual perception [5], motion perception [6,21], and attentional processes [29], as well as to study the hemispheric lateralization and anatomical localization of object-related visual working memory tasks [20], the involvement of parietal cortex in novel [1] and learned [37,39] visual search tasks, the anatomic and physiologic localization of speech arrest [14], the functional relevance of primary motor cortex activation for mental rotation [16], the contribution of posterior parietal cortex (PPC) to eye-hand coordination processes [36], the contribution of visual cortex to tactile discrimination [41], the processing of visual information [3], and the execution of hand [12] and eye movements [32].

Some studies combined TMS with simultaneous func- tional neuroimaging in order to stimulate and image the brain at the same time and to obtain 3D maps of the magnetic field created by TMS coils [7,8]. Beside the demonstration of a general technical feasibility of interleaving TMS with fMRI, Bohning et al. [7] were able to produce dose-dependent changes in local brain activity. The blood flow changes induced by TMS were comparable to those induced by behavioural or cognitive tasks $[7,8]$.

Compared to studies that combine functional imaging with neuropsychological deficits occurring in structural brain damage [30], the functional deficits induced by TMS are far more transient, and therefore its effect is unlikely to bring about functional reorganization [38] or the functional impairment of remote areas (diaschisis) [33]. Using rTMS we can thus study the contribution of brain areas that have been identified by functional neuroimaging to the performance of a specific task [18,23].

In the present study, we attempted to demonstrate that the well-confirmed activation in the parietal cortex during the performance of visuospatial tasks underlies the taskrelated processing of visual information and can therefore be considered the causal source of visuospatial abilities. Subjects saw sequences of coloured clocks and performed a task that required them to discriminate angles, colours, or conjunctions of both. The study consists of two experiments. In the first experiment subjects had to perform the tasks during fMRI in order to localize the areas of activation during the execution of the different tasks. In the second experiment a different set of subjects performed the same tasks before (pre-test) and after (post-test) having received real or sham rTMS at $1 \mathrm{~Hz}$ to the activated sites. The colour discrimination task serves as a control task for the specificity of the TMS effect to visuospatial tasks. A differential effect of real rTMS on reaction times of the angle discrimination and colour task conditions was assumed to support our hypothesis that parietal activation not only accompanies, but subserves the performance of visuospatial tasks and that rTMS as an experimental tool has the potential to influence higher cognitive functions such as visuospatial information processing.

\section{Materials and methods}

\subsection{FMRI and rTMS experiments}

\subsubsection{Cognitive tasks}

The stimuli consisted of analogue clocks with a yellow face and two white or yellow hands. The angle between the hands varied in steps of $30^{\circ}$. Subjects had to press a button whenever a target stimulus appeared. Targets were defined as clocks with angles of 60 or $30^{\circ}$ (angle discrimination task), clocks with white hands (colour discrimination task), or both (conjunction task). Stimuli were generated using the STIM software package (Neuroscan, Hernon, USA). Stimuli were shown for $800 \mathrm{~ms}$ with an interstimulus 
interval of $1.2 \mathrm{~s}$. In each condition, $20 \%$ of the presented stimuli were target stimuli. Note that only the targetdefining cue varied between conditions, while the stimuli were physically identical.

Both experiments were conducted in accordance with the Declaration of Helsinki and approved by the local ethics committee. All subjects gave their informed consent to participate in the respective study and reported being in good health and free of any psycho-active medication. There had been no incident of prior neurological disorder, including seizures, in any of the subjects.

\section{2. fMRI-experiment}

\subsubsection{Subjects}

Six healthy subjects were recruited (mean age 27.5 years, range: 26-31 years; all male). Volunteers were naive within the limits of informed consent.

\subsubsection{Apparatus and procedure}

MRI data were acquired with a $1.5 \mathrm{~T}$ MAGNETOM Vision MRI scanner (Siemens Medical Systems, Erlangen, Germany) using the standard head coil. For functional imaging we used a gradient echo EPI sequence (1 volume $=15$ axial slices parallel to the plane crossing the anterior and posterior commissure, repetition time/echo time $[\mathrm{TR} / \mathrm{TE}]=4000 \mathrm{~ms} / 69 \mathrm{~ms}$, flip angle $[\mathrm{FA}]=90^{\circ}$, field of view $[\mathrm{FoV}]=210 \times 210 \mathrm{~mm}^{2}$, voxel size $=1.6 \times 1.6 \times 5.0$ $\mathrm{mm}^{3}$ ). Functional time-series consisted of 128 volumes and lasted 512 s. A T1-weighted 3D MP-RAGE scan was recorded in the same session (voxel size $=1 \times 1 \times 1 \mathrm{~mm}^{3}$ ). Subjects were asked to keep their eyes steady during scanning. Off-line electrooculography recordings showed absence of differences in saccade rate between conditions.

\subsubsection{Design}

The three different conditions (angle, conjunction, colour) were tested in one session following the classical block design (four separate blocks in a pseudorandom order, each lasted $20 \mathrm{~s}$ and contained 10 stimuli, altogether 12 blocks). Stimuli were delivered to a high luminance LCD projector (EIKI LC-6000). The images were backprojected onto a frosted screen positioned at the foot end of the scanner and viewed by the subjects through a mirror placed on the head coil.

\subsubsection{Statistical analyses}

FMRI-data analysis and visualization was performed using the BrainVoyager 3.7 software package. Spatial and temporal smoothing, removal of linear trends, motion correction, Talairach transformation of 3D anatomical data sets and generation of 3D functional data sets (volume time courses) followed procedures published elsewhere [17,24].

The statistical analysis of the variance of the BOLD signal was based on the application of multiple regression analysis to time series of task-related functional activation
[15]. The general linear model (GLM) of the experiment was computed from the six (one for each subject) $z$ normalized volume time courses. $z$-Normalization of the BOLD signal was performed subject by subject for each voxel time course. The signal values during the angle detection, colour detection, and conjunction task conditions were considered the effects of interest. The corresponding predictors, obtained by convolution of an ideal box-car response (assuming the value 1 for the time-points of task presentation and the value 0 for the remaining time points) with a linear model of the hemodynamic response [9], were used to build the design matrix of the experiment. The global level of the signal time-courses in each session was considered to be a confounding effect. To analyse the effects of each separate condition compared to baseline, 3D group statistical maps were generated by associating each voxel with the $F$ value corresponding to the specified set of predictors and calculated on the basis of the least mean squares solution of the GLM. Voxels were only accepted as activated when the associated $P$-value was $<3.591 \times 10^{-13}$ (uncorrected, corresponding to a multiple regression coefficient $R>0.3$ ) and they formed part of a cluster of $200 \mathrm{~mm}^{3}$ or more (Table 2). Furthermore, in areas that were significantly activated during more than one condition, statistical comparisons were performed on the basis of the mean time course of all voxels of an analysed area. Values of percent signal change averaged over subjects were computed on the basis of the difference between the mean values of the fMRI signal in each experimental condition and the mean fMRI signal in the baseline periods for each individual subject [17]. These values were analysed using analysis of variance (ANOVA) and a post hoc pairwise comparison with stimulus condition as a within-group factor and correction of $P$-values for multiple comparisons (Table 2, contrasts).

\section{3. $r$-TMS-experiment}

\subsubsection{Subjects}

Twenty subjects volunteered to participate (mean age: 28 years, range: 19-44 years; nine males, 11 females).

\subsubsection{Apparatus and procedure}

A custom TMS stimulator (MagPro, Medtronic Functional Diagnostics, Skovlunde, Denmark) was used to generate repetitive biphasic magnetic pulses. Magnetic pulses were delivered with a figure-eight-coil (Magnetic Coil Transducer MC-B70, Medtronic) with an outer radius of $50 \mathrm{~mm}$. Individual motor thresholds were identified by stimulating the motor cortex with single TMS pulses until a movement of the contralateral thumb was detected in relaxed muscle state. For real rTMS, the centre of the coil was held tangentially to the skull over parietal cortex $(\mathrm{Pz})$. For sham rTMS, the coil was moved downwards from $\mathrm{Pz}$ by $3 \mathrm{~cm}$ and rotated so that the edge of the two wings of the coil rested at $90^{\circ}$ on the scalp. In this sham rTMS 
condition, the induced magnetic field did not enter the brain, although the touch on the scalp and the sound of the coil are comparable to those in the real rTMS condition [23].

During the experiment the coil was fixed in position and subjects were asked to keep their eyes steady throughout the experiment. Repetitive TMS was delivered at $80 \%$ of the subject's motor threshold, a field intensity sufficient to influence cortical activity [43], at $1-\mathrm{Hz}$ stimulation frequency, in a single train of $10 \mathrm{~min}$ duration, in accordance with international safety standards of rTMS experimentation [40]. Overall each subject received 600 stimuli. These stimulation parameters produce effects that last after the stimulation period $[18,23]$.

\subsubsection{Design}

Every clock reading task (angle, conjunction, colour) consisted of three blocks, each containing 20 stimuli (60 stimuli). The whole sequence thus consisted of 180 stimuli. Before every block, the target-defining cue was presented. The trial sequence of the blocks as well as the sequence within each block was randomized.

Subjects were randomly assigned to one of two groups. One group was stimulated with real rTMS (stimulationgroup), while the other group received sham rTMS stimulation (control-group).

We repeatedly measured the subject's performance in the three different tasks, before and after the stimulation or before and after the sham condition, respectively, in order to compare possible differences in the change of the task performances from pre-test to post-test between the two groups (Table 1).

\subsubsection{Statistical analyses}

Mean reaction times for correctly detected target stimuli were computed by task condition and subject. Mean reaction times in the pre-test were compared to mean reaction times in the post-test for each group and task condition by calculating the difference between the two test times. A two-way ANOVA for repeated measurements was computed to test for a significant interaction of the two factors of the experimental design (Table 1).

\section{Results}

\section{1. fMRI-experiment}

All three task conditions (angle, conjunction, and colour), compared to baseline, were accompanied by an increase in the BOLD signal in striate and extrastriate visual cortex (Fig. 1), inferior parietal lobule (IPL), primary motor cortex (PMC), the frontal eye fields (FEF), and the supplementary motor area (SMA). The angle and conjunction detection tasks showed additional activation of regions in SPL bilaterally (Table 2).

The comparison between BOLD signal changes for the different conditions in visual cortical areas revealed that the overall activation level tended to be higher during the angle and conjunction than during the colour condition (Table 2, contrasts). This effect was particularly pronounced in the left intraparietal sulcus (IPS), an area of SPL where signal changes were consistently highest for the angle condition, followed by the conjunction and colour conditions (Figs. 1 and 2) and was also observed in the FEF bilaterally (Table 2). Other parietal areas, including the IPL bilaterally, did not show a significant difference between the angle and conjunction conditions. On the other hand, the activation of the fusiform gyrus in the occipitotemporal ventral stream were roughly equal for all conditions (Table 2, contrasts). PMC and SMA did not show task specific differences.

\section{2. rTMS-experiment}

In order to analyse the change of the reaction time from pre-test to post-test in the rTMS-experiment, we subtracted the mean reaction time in the post-test from the mean reaction time in the pre-test for every task independently for both groups. A negative difference means an increase of the reaction time in the post-test while a positive

Table 1

Multivariate two-factorial design

\begin{tabular}{|c|c|c|c|}
\hline & Pre-test & Treatment & Post-test \\
\hline Stimulation-group & $\begin{array}{l}\text { Visuo-spatial tasks: } \\
\text { angle, conjunction } \\
\text { Non-visuo-spatial task: } \\
\text { colour }\end{array}$ & real rTMS & $\begin{array}{l}\text { Visuo-spatial tasks: } \\
\text { angle, conjunction } \\
\text { Non-visuo-spatial task: } \\
\text { colour }\end{array}$ \\
\hline Control-group & $\begin{array}{l}\text { Visuo-spatial tasks: } \\
\text { angle, conjunction } \\
\text { Non-visuo-spatial task: } \\
\text { colour }\end{array}$ & sham rTMS & $\begin{array}{l}\text { Visuo-spatial tasks: } \\
\text { angle, conjunction } \\
\text { Non-visuo-spatial task: } \\
\text { colour }\end{array}$ \\
\hline
\end{tabular}

Randomly assigned group comparison factor (two levels: real rTMS, sham rTMS); factor of repeated measurement (two levels: pre-test, post-test). Notes: Angle: angle discrimination in the clock reading task (targets $=$ hands with angles of 30 or $60^{\circ}$ ). Colour: colour discrimination in the clock reading task (targets $=$ white hands). Conjunction: combined angle and colour discrimination in the clock reading task (targets $=$ white hands with 30 or $60^{\circ}$ ). 


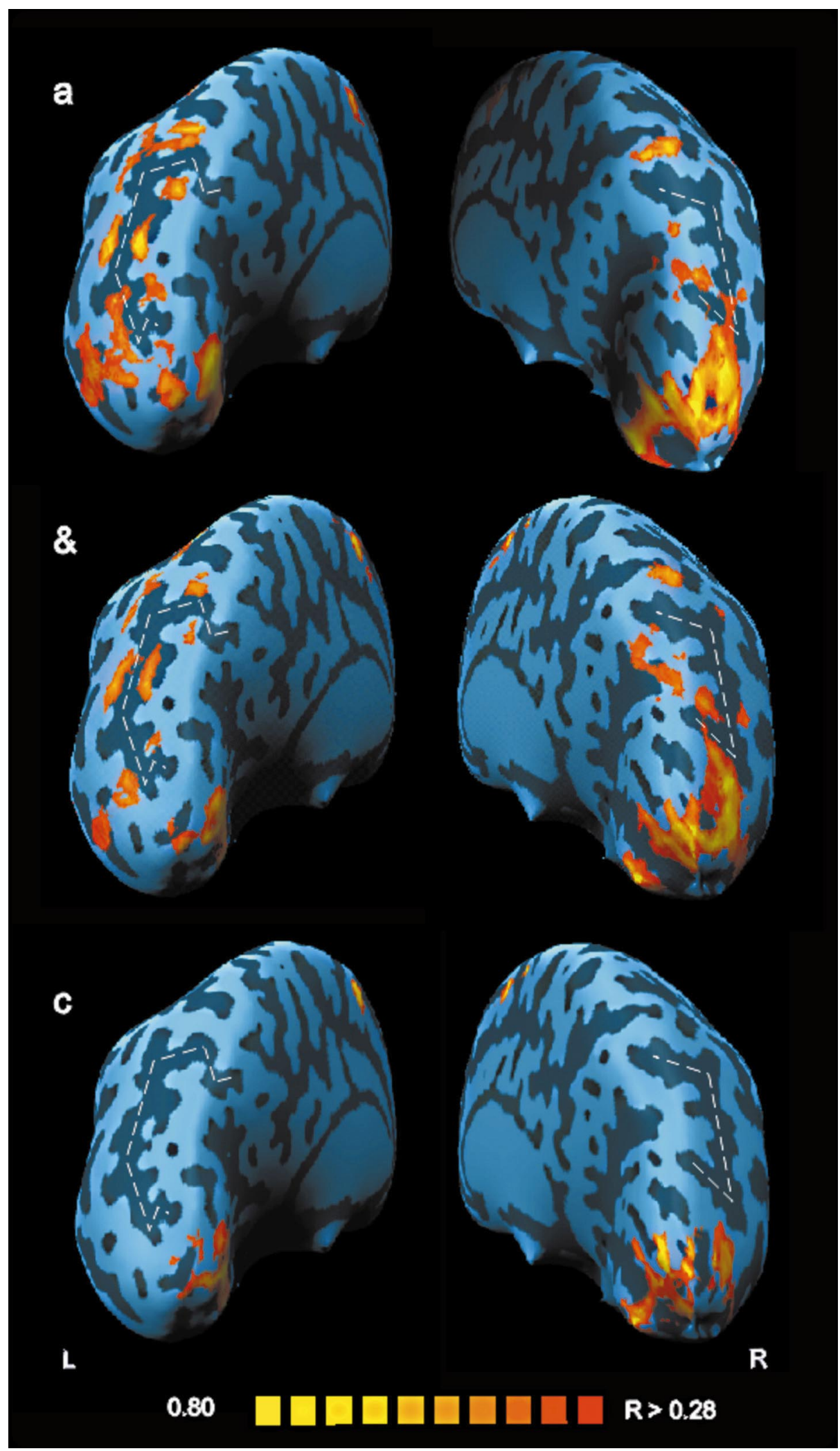

Fig. 1. Group analysis (GLM) for six subjects at $F(6,743)=10.95\left(P=10^{-11}\right.$, uncorrected). Colour coded group statistical maps (see Materials and Methods) of BOLD signal increase for task vs. baseline (predictors: a =angle, $\&=$ conjunction, $\mathrm{c}=$ colour) superimposed on the inflated hemispheres of a single subject. View from the occipital pole. The white lines indicate the descending portions of the intraparietal sulci. 
Table 2

Talairach coordinates

\begin{tabular}{|c|c|c|c|c|c|c|c|c|c|c|c|c|c|}
\hline \multirow[t]{2}{*}{ Anatomical area } & \multirow[t]{2}{*}{ BA } & \multicolumn{3}{|c|}{ Colour vs. baseline } & \multicolumn{3}{|c|}{ Angle vs. baseline } & \multicolumn{3}{|c|}{ Conjunction vs. baseline } & \multicolumn{3}{|c|}{ Contrast } \\
\hline & & $X$ & $Y$ & $Z$ & $X$ & $Y$ & $Z$ & $X$ & $Y$ & $Z$ & 1 & 2 & 3 \\
\hline \multirow[t]{2}{*}{ Left posterior parietal cortex } & \multirow[t]{2}{*}{7} & \multirow[t]{2}{*}{-} & \multirow[t]{2}{*}{-} & \multirow[t]{2}{*}{-} & -19 & -74 & 47 & -26 & -75 & 46 & \multirow[t]{2}{*}{ A } & \multirow[t]{2}{*}{ A } & \multirow[t]{2}{*}{-} \\
\hline & & & & & -29 & -74 & 22 & -32 & -75 & 23 & & & \\
\hline \multirow[t]{2}{*}{ Right posterior parietal cortex } & \multirow[t]{2}{*}{7} & \multirow[t]{2}{*}{-} & \multirow[t]{2}{*}{-} & \multirow[t]{2}{*}{-} & 26 & -69 & 48 & 29 & -67 & 53 & \multirow[t]{2}{*}{ A } & \multirow[t]{2}{*}{-} & \multirow[t]{2}{*}{-} \\
\hline & & & & & 29 & -78 & 21 & 26 & -75 & 23 & & & \\
\hline \multirow[t]{2}{*}{ Left inferior parietal lobule } & \multirow[t]{2}{*}{40} & \multirow[t]{2}{*}{-40} & \multirow[t]{2}{*}{-43} & \multirow[t]{2}{*}{53} & -38 & -49 & 56 & -42 & -46 & 54 & - & - & \multirow[t]{2}{*}{$\&$} \\
\hline & & & & & -34 & -45 & 44 & -34 & -45 & 44 & - & - & \\
\hline Right inferior parietal lobule & 40 & - & - & - & 37 & -50 & 47 & - & - & - & - & - & $\&$ \\
\hline \multirow[t]{2}{*}{ Left superior frontal gyrus (SMA) } & \multirow[t]{2}{*}{$6 / 8$} & -3 & -8 & 52 & -1 & -8 & 53 & -2 & -6 & 55 & - & - & - \\
\hline & & & & & & & & -1 & 6 & 47 & - & - & - \\
\hline Right superior frontal gyrus (SMA) & $6 / 8$ & 4 & -8 & 51 & 4 & -9 & 52 & 6 & -5 & 51 & - & - & - \\
\hline Left precentral sulcus (FEF) & 6 & -59 & 2 & 24 & -56 & 0 & 32 & -58 & 2 & 30 & A & - & - \\
\hline Right precentral sulcus (FEF) & 6 & 56 & 2 & 31 & 48 & 2 & 35 & 49 & 4 & 34 & A & A & - \\
\hline Left middle frontal gyrus & 44 & - & - & - & - & - & - & -50 & 25 & 29 & - & - & - \\
\hline Left precentral gyrus (PMC) & 4 & -39 & -20 & 55 & -38 & -19 & 55 & -36 & -17 & 55 & - & - & - \\
\hline Right precentral gyrus (PMC) & 4 & 36 & -13 & 60 & 32 & -16 & 55 & 35 & -13 & 57 & - & - & - \\
\hline Left occipital lobe & $17 / 18$ & -11 & -75 & -9 & -7 & -88 & -5 & -17 & -71 & -13 & A & - & - \\
\hline Right occipital lobe & $17 / 18$ & 9 & -73 & -9 & 5 & -81 & -3 & 5 & -80 & -7 & A & A & - \\
\hline Left occipitotemporal cortex & $37 / 19$ & - & - & - & -46 & -73 & -6 & -46 & -73 & -5 & A & - & - \\
\hline Right occipitotemporal cortex & $37 / 19$ & - & - & - & 37 & -77 & -2 & 35 & -76 & -5 & A & - & - \\
\hline Left middle occipital gyrus & 19 & - & - & - & -26 & -91 & 9 & -23 & -90 & 11 & A & - & $\&$ \\
\hline Right middle occipital gyrus & 19 & 24 & -90 & 11 & 21 & -91 & 12 & 27 & -89 & 6 & A & A & - \\
\hline Left fusiform gyrus & 37 & -30 & -51 & -18 & -30 & -52 & -18 & -28 & -58 & -18 & - & - & - \\
\hline Right fusiform gyrus & 37 & 21 & -53 & -18 & 20 & -50 & -15 & 24 & -54 & -18 & - & - & - \\
\hline
\end{tabular}

Talairach coordinates of centres of mass of activated clusters $>200 \mathrm{~mm}^{3}$ (at $F=12.25, R>0.3$; six subjects) of the condition vs. baseline maps. Contrast: comparison of signal change from baseline for (1) angle (A) vs. colour (C); (2) angle vs. conjunction (\&); (3) conjunction vs. colour. A, C, \& indicate the larger value. $P<0.05$ post hoc paired $t$-tests. Empty fields indicate that differences in signal change from baseline between experimental conditions did not reach significance. $\mathrm{BA}=$ Brodmann area.

difference means a decrease of reaction time in the posttest (Fig. 3).

The stimulation-group showed virtually no change in reaction time from pre-test to post-test in the colour discrimination $(+5.3 \mathrm{~ms})$ and the conjunction task $(-1.6$ $\mathrm{ms})$ and even an increased reaction time in the post-test in the angle discrimination task $(-28.1 \mathrm{~ms})$. The controlgroup, on the other hand, showed a decrease in reaction time in all three tasks $(+49.4 \mathrm{~ms}$ in the angle discrimination task; $+26.8 \mathrm{~ms}$ in the colour discrimination task; $+57.9 \mathrm{~ms}$ in the conjunction task). This decrease in reaction time was probably due to a familiarization effect. The difference in the change from pre-test to post-test between stimulation and control-group was highest in the angle discrimination task $(77.5 \mathrm{~ms})$, followed by the conjunction task (59.4 ms), while the colour discrimination task showed almost no difference between the two groups (21.4 ms). These results suggest a difference in the change from pre-test to post-test between the two groups as expected by the hypotheses.

The two-way ANOVA for repeated measurements revealed that the differences between the stimulation and control groups in the change of reaction time from pre-test to post-test were only significant for the angle discrimination task $[F(1,18)=11.8 ; P=0.003]$ and the conjunction task $[F(1,18)=6.1 ; P=0.024]$, while the colour discrimina- tion task $[F(1,18)=0.92 ; P=0.35]$ showed no significant statistical difference between the groups.

\section{Discussion}

The analysis of the BOLD signal changes associated with the different conditions of the cognitive paradigm reveals that a significant activation of SPL occurred only during the conditions involving a visuospatial judgement (angle and conjunction), in accordance with prior results $[11,17,19,28]$, while brain areas subserving elementary visual processing (striate and extrastriate visual cortex), and motor responses (PMC) were activated in all conditions. The higher activation level in the FEF during the angle condition compared to the colour (bilaterally) and conjunction (only right FEF) conditions might reflect differences in spatial attention or maintenance of spatial information between the tasks $[17,42]$. In the IPS, both contrast effects and signal amplitude were highest during the angle discrimination task, followed by the conjunction task, where visuospatial features contributed only part of the task-relevant information. These different activation patterns cannot be attributed to changes in the composition of the visual stimulus, because stimuli were kept physically identical across conditions and only the cue and the 


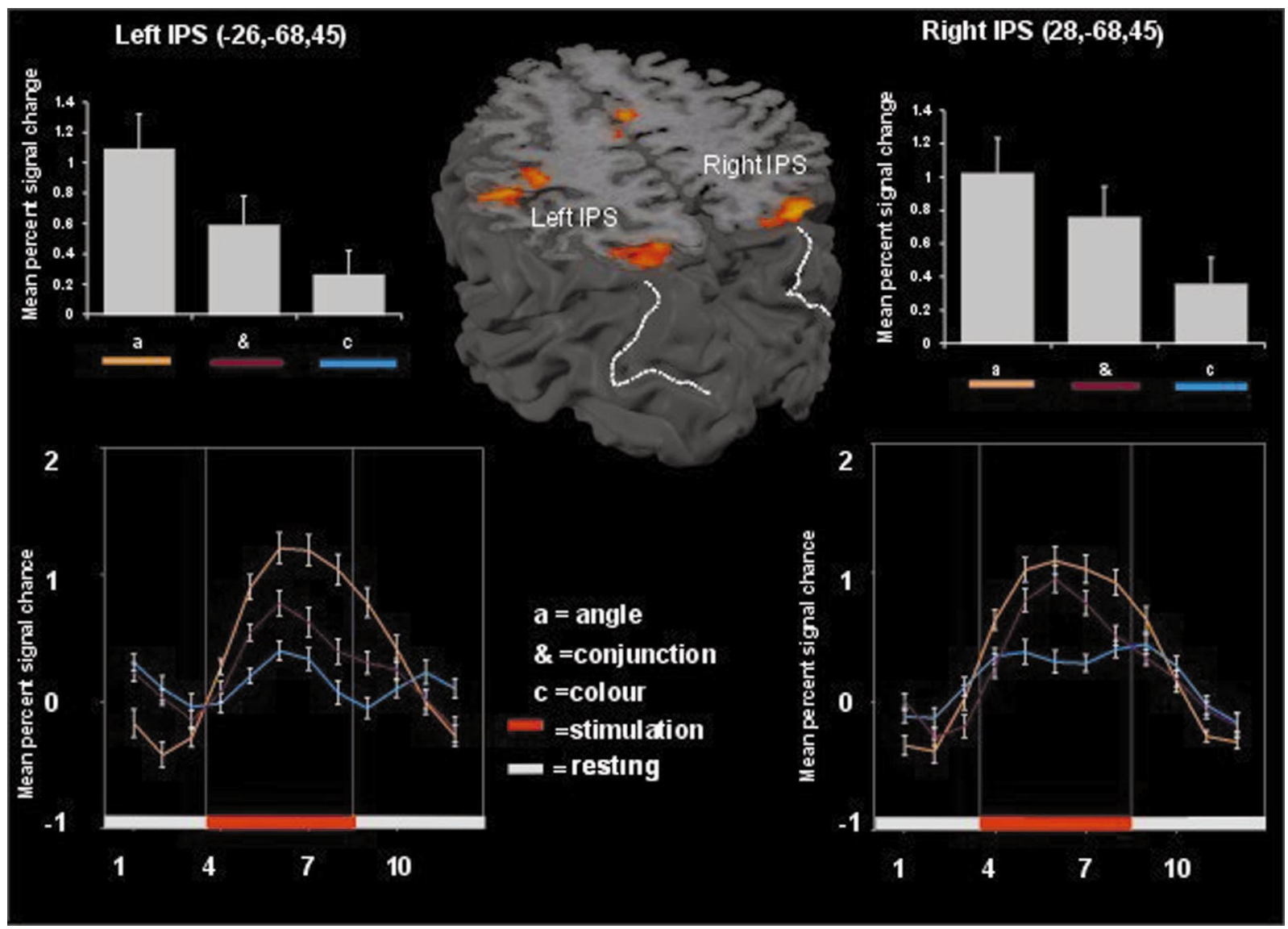

Fig. 2. Centre: Axial cut (at Talairach $z=45$ ) through a surface reconstruction of the brain of one of the subjects showing the group activation map (thresholded at $R=0.3$, corresponding to an uncorrected $P$-value $=3.591 \times 10^{-13}$ ) for angle condition versus baseline. Left and right: BOLD signal time courses in the left and right IPS averaged over six subjects (bottom) and box plots (top) of mean activation levels during the angle, conjunction, and colour conditions in the IPS areas. Mean percent signal change and standard deviation are displayed on the $y$-axis for each condition.

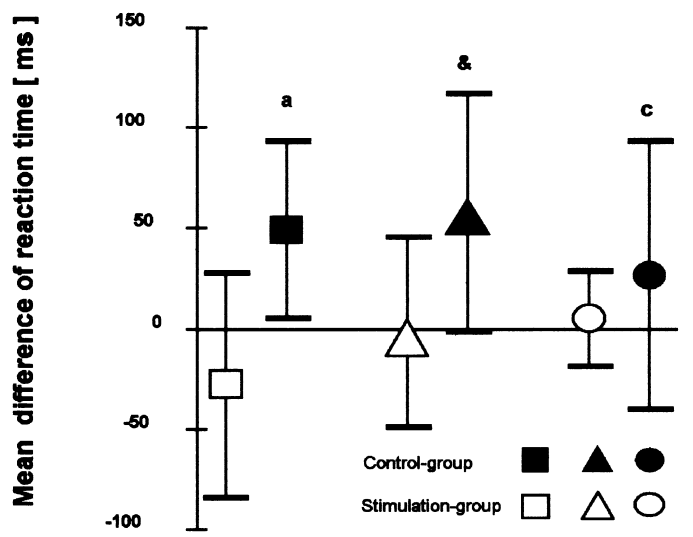

Fig. 3. Comparison of the mean differences between the reaction times in the pre-test and in the post-test calculated for both groups and each test. Negative differences mean increases in reaction time and vice versa. As a reference, the line of no difference (pre-test minus post-test $=0$ ) is drawn in the figure. Error bars denote standard deviation. task given to the subjects varied. Therefore the BOLD activation levels in SPL reflect a modulation of cortical activity that is related to the visuospatial component, which is a specific task-relevant feature of only two of the used conditions.

By using low-frequency rTMS we were able to inhibit the excitability $[10,23]$ of the parietal cortex as an independent variable and examine the influence of this manipulation of cortical excitability on the performance of two visuospatial tasks as dependent variables. To control the specific effect of the manipulation on visuospatial tasks, a non-visuospatial task was included in the experimental design.

The control-group, (sham rTMS) performed faster in all tasks after the stimulation session (post-test), which can be attributed to familiarization with the tasks. The stimulation-group, whose SPL had been exposed to real rTMS, performed more slowly in both the angle and conjunction task. The colour discrimination task was unaffected. The significant two-factor interaction in the ANOVA could thus show that decreased excitability of SPL reduces the performance of visuospatial tasks (angle, 
conjunction), but not that of visual tasks which do not require the analysis of the spatial features of the stimulus (colour).

These findings not only show that the parietal cortex is activated when healthy volunteers perform visuospatial tasks, but also suggest that performance of these tasks is impaired when neural activity in this region of cortex is disrupted by rTMS. This provides a strong evidence for a causal relationship of parietal cortex activation and visuospatial abilities.

By combining fMRI and rTMS within one experimental design this study reveals that rTMS has the potential of taking functional neuroimaging one step further by elucidating causal relationships between neural activation and cognitive function [18].

The presented results encourage investigations of potential hemispheric differences in the functional relevance of parietal cortex in visuospatial functioning. Moreover, the timing of visuospatial information processing in the parietal cortex can be proved single-pulse TMS. Further studies might also investigate whether the specificity of the TMS effect is due to a disruption of the task performance itself or of a task training effect. A follow up study designed to distinguish explicitly between subjects trained to perform the task at ceiling and non-trained subjects could lead to such a differentiation of the described effects.

\section{Acknowledgements}

This study was supported by the Alzheimer Research Centre, Frankfurt am Main, Germany and the Alzheimer Forschung Initiative e.V. The authors are grateful to Lars Muckli for suggestions concerning the stimuli and to Heather Drewett and Aistis Bieri for comments on the manuscript.

\section{References}

[1] E. Ashbridge, V. Walsh, A. Cowey, Temporal aspects of visual search studied by transcranial magnetic stimulation, Neuropsychologia 35 (1997) 1121-1131.

[2] B. Alivisatos, M. Petrides, Functional activation of the human brain during mental rotation, Neuropsychologia 35 (1997) 111-118.

[3] V.E. Amassian, R.Q. Cracco, P.J. Maccabee, J.B. Cracco, A. Rudell, L. Eberle, Suppression of visual perception by magnetic coil stimulation of human occipital cortex, Electroencephalogr. Clin. Neurophysiol. 74 (1989) 458-462.

[4] V.E. Amassian, P.J. Maccabee, R.Q. Cracco, J.B. Cracco, A. Rudell, L. Eberle, Measurement of information processing delays in human visual cortex with repetitive magnetic coil stimulation, Brain Res. 605 (1993) 317-321.

[5] V.E. Amassian, R.Q. Cracco, P.J. Maccabee, J.B. Cracco, A. Rudell, L. Eberle, Unmasking human visual perception with the magnetic coil and its relationship to hemispheric asymmetry, Brain Res. 605 (1993) 312-316.

[6] G. Beckers, S. Zeki, The consequences of inactivating areas V1 and V5 on visual motion perception, Brain 118 (1995) 49-60.
[7] D.E. Bohning, A. Shastri, K.A. McConnell, Z. Nahas, J.P. Lorberbaum, D.R. Roberts, C. Teneback, D.J. Vincent, M.S. George, A combined TMS/fMRI study of intensity-dependent TMS over motor cortex, Biol. Psychiatry 45 (1999) 385-394.

[8] D.E. Bohning, A. Shastri, E.M. Wassermann, U. Ziemann, J.P. Lorberbaum, Z. Nahas, M.P. Lomarev, M.S. George, BOLD-fMRI response to single-pulse transcranial magnetic stimulation (TMS), J. Magn. Reson. Imaging 11 (2000) 569-674.

[9] G.M. Boynton, S.A. Engel, G.H. Glover, D.J. Heeger, Linear systems analysis of functional magnetic resonance imaging in human V1, J. Neurosci. 16 (1996) 4207-4221.

[10] R. Chen, J. Classen, C. Gerloff, P. Celnik, E.M. Wassermann, M. Hallett, L.G. Cohen, Depression of motor cortex excitability by low-frequency transcranial magnetic stimulation, Neurology 48 (1997) 1398-1403.

[11] M.S. Cohen, S.M. Kosslyn, H.C. Breiter, G.J. DiGirolamo, W.L. Thompson, A.K. Anderson, S.Y. Brookheimer, B.R. Rosen, J.W. Belliveau, Changes in cortical activity during mental rotation. A mapping study using functional MRI, Brain 119 (1996) 89-100.

[12] M. Desmurget, C.M. Epstein, R.S. Turner, C. Prablanc, G.E. Alexander, S.T. Grafton, Role of the posterior parietal cortex in updating reaching movements to a visual target, Nat. Neurosci. 2 (1999) 563-567.

[13] T. Dierk, D.E.J. Linden, A. Hertl, T. Günther, H. Lanfermann, A. Niesen, L. Frölich, F.E. Zanella, G. Hör, R. Goebel, K. Maurer, Multimodal imaging of residual function and compensatory resource allocation in cortical atrophy: a case study of parietal lobe function in a patient with Huntington's, Psychiatry Res. 90 (1999) 67-75.

[14] C.M. Epstein, K.J. Meador, D.W. Loring, R.J. Wright, J.D. Weissman, S. Sheppard, J.J. Lah, F. Puhalovich, L. Gaitan, K.R. Davey, Localization and characterization of speech arrest during transcranial magnetic stimulation, Clin. Neurophysiol. 110 (1999) 1073-1079.

[15] K.J. Friston, A.P. Holmes, J.B. Poline, P.J. Grasby, S.C. Williams, R.S. Frackowiak, R. Turner, Analysis of fMRI time-series revisited, Neuroimage 2 (1995) 45-53.

[16] G. Ganis, J.P. Keenan, S.M. Kosslyn, A. Pascual-Leone, Transcranial magnetic stimulation of primary motor cortex affects mental rotation, Cereb. Cortex 10 (2000) 175-180.

[17] R. Goebel, D.E.J. Linden, H. Lanfermann, F.E. Zanella, W. Singer, Functional imaging of mirror and inverse reading reveals separate coactivated networks for oculomotion and spatial transformations, Neuroreport 9 (1998) 713-719.

[18] M. Hallett, Transcranial magnetic stimulation and the human brain, Nature 406 (2000) 147-150

[19] J.V. Haxby, B. Horwitz, L.G. Ungerleider, J.M. Maisog, P. Pietrini, C.L. Grady, The functional organization of human extrastriate cortex: a PET-rCBF study of selective attention to faces and locations, J. Neurosci. 14 (1994) 6336-6353.

[20] K.S. Hong, S.K. Lee, J.Y. Kim, K.K. Kim, H. Nam, Visual working memory revealed by repetitive transcranial magnetic stimulation, $\mathrm{J}$. Neurol. Sci. 181 (2000) 50-55.

[21] J. Hotson, D. Braun, W. Herzberg, D. Boman, Transcranial magnetic stimulation of extrastriate cortex degrades human motion direction discrimination, Vision Res. 34 (1994) 2115-2123.

[22] P. Jennum, H. Winkel, A. Fuglsang-Frederiksen, Repetitive magnetic stimulation and motor evoked potentials, Electroencephalogr. Clin. Neurophysiol. 97 (1995) 96-101.

[23] S.M. Kosslyn, A. Pascual-Leone, O. Felician, S. Camposano, J.P. Keenan, W.L. Thompson, G. Ganis, K.E. Sukel, N.M. Alpert, The role of area 17 in visual imagery: convergent evidence from PET and rTMS, Science 284 (1999) 167-170.

[24] D.E.J. Linden, D. Prvulovic, E. Formisano, M. Völlinger, F.E. Zanella, R. Goebel, T. Dierks, The functional neuroanatomy of target detection: an fMRI study of visual and auditory oddball tasks, Cereb. Cortex 8 (1999) 815-823.

[25] F. Maeda, J.P. Keenan, J.M. Tormos, H. Topka, A. Pascual-Leone, Modulation of corticospinal excitability by repetitive transcranial magnetic stimulation, Clin. Neurophysiol. 111 (2000) 800-805. 
[26] A. Pascual-Leone, J. Valls-Sole, E.M. Wassermann, M. Hallett, Responses to rapid-rate transcranial magnetic stimulation of the human motor cortex, Brain 117 (1994) 847-858.

[27] A. Pascual-Leone, J.M. Tormos, J. Keenan, F. Tarazona, C. Canete, M.D. Catala, Study and modulation of human cortical excitability with transcranial magnetic stimulation, J. Clin. Neurophysiol. 15 (1998) 333-343.

[28] R.A. Poldrack, J.E. Desmond, G.H. Glover, J.D. Gabrieli, The neural basis of visual skill learning: an fMRI study of mirror reading, Cereb. Cortex 8 (1998) 1-10.

[29] M.I. Posner, J.A. Walker, F.J. Friedrich, R.D. Rafal, Effects of parietal injury on covert orienting of attention, J. Neurosci. 4 (1984) $1863-1874$

[30] C.J. Price, C.J. Mummery, C.J. Moore, R.S. Frakowiak, K.J. Friston, Delineating necessary and sufficient neural systems with functional imaging studies of neuropsychological patients, J. Cogn. Neurosci. 11 (1999) 371-382.

[31] M.E. Raichle, Behind the scenes of functional brain imaging: a historical and physiological perspective, Proc. Natl. Acad. Sci. USA 95 (1998) 765-772.

[32] T. Ro, S. Cheifet, H. Ingle, R. Shoup, R. Rafal, Localization of the human frontal eye fields and motor hand area with transcranial magnetic stimulation and magnetic resonance imaging, Neuropsychologia 37 (1999) 225-231.

[33] R.J. Seitz, N.P. Azari, U. Knorr, F. Binkofski, H. Herzog, H.J. Freund, The role of diaschisis in stroke recovery, Stroke 30 (1999) $1844-1850$.

[34] E. Shikata, F. Hamzei, V. Glauche, R. Knab, C. Dettmers, C. Weiller, C. Büchel, Surface orientation discrimination activates caudal and anterior intraparietal sulcus in humans: an event-related fMRI study, J. Neurophysiol. 85 (2001) 1309-1314.
[35] L. Trojano, D. Grossi, D.E.J. Linden, E. Formisano, H. Hacker, F.E. Zanella, R. Goebel, F. Di Salle, Matching two imagined clocks. The functional anatomy of spatial analysis in the absence of visual stimulation, Cereb. Cortex 10 (2000) 473-481.

[36] P. van Donkelaar, J.H. Lee, A.S. Drew, Transcranial magnetic stimulation disrupts eye-hand interactions in the posterior parietal cortex, J. Neurophysiol. 84 (2000) 1677-1680.

[37] V. Walsh, E. Ashbridge, A. Cowey, Cortical plasticity in perceptual learning demonstrated by transcranial magnetic stimulation, Neuropsychologia 36 (1998) 45-49.

[38] V. Walsh, M. Rushworth, A primer of magnetic stimulation as a tool for neuropsychology, Neuropsychologia 37 (1999) 125-135.

[39] V. Walsh, A. Ellison, E. Ashbridge, A. Cowey, The role of the parietal cortex in visual attention - hemispheric asymmetries and the effects of learning: a magnetic stimulation study, Neuropsychologia 37 (1999) 245-251.

[40] E.M. Wassermann, Risk and safety of repetitive transcranial magnetic stimulation: report and suggested guidelines from the International Workshop on the Safety of Repetitive Transcranial Magnetic Stimulation, Electroencephalogr. Clin. Neurophysiol. 108 (1998) $1-16$.

[41] A. Zangaladze, C.M. Epstein, S.T. Grafton, K. Sathian, Involvement of visual cortex in tactile discrimination of orientation, Nature 401 (1999) 587-590.

[42] E. Zarahn, G. Aguirre, M. D'Esposito, Replication and further studies of neural mechanisms of spatial mnemonic processing in humans, Brain Res. Cogn. Brain Res. 9 (2000) 1-17.

[43] U. Ziemann, J.C. Rothwell, M.C. Ridding, Interaction between intracortical inhibition and facilitation in human motor cortex, J. Neurosci. 496 (1996) 873-881. 